\title{
Los hijos de los hijos de la clase obrera: fantasmas, barrios e impostores en la ficción literaria del siglo XXI
}

\section{Children of the Working-Class Children: Ghosts, Suburbs and Impostors in the 21st-Century Fiction}

\author{
Ángela Martínez Fernández [Angela.Martinez-Fernandez@uv.es] \\ Universitat de València, España
}

\section{RESUMEN}

El presente artículo tiene como objetivo señalar e indagar en algunas de las líneas generales de reflexión que desarrollan las narrativas "jóvenes" del último milenio y, concretamente, el modo en que todas ellas intervienen en la batalla por los sentidos de lo obrero. Se propone una ruta de análisis de algunas novelas recientes donde el vector de la clase social actúa como foco, como eje ordenador, pero de una forma particular y concreta, ineludiblemente característica del nuevo milenio. Para observar el marco de referencia que algunos "hijos de los hijos de la clase obrera" construyen en el terreno literario, escogemos la novela de Anna Pacheco (Listas, guapas, limpias, 2019) como herramienta ejemplarizante, es decir, como soporte desde el que profundizar en las estrategias ficcionales y colectivas que acontecen en torno al origen de clase. A través de ella, pues, ahondamos en el análisis de los nuevos marcos de referencia que toman forma en el último siglo y que trabajan de forma particular con el referente obrero.

\section{Palabras clave}

Listas, guapas, limpias; clase social; campo cultural; memoria obrera; repolitización

\begin{abstract}
This article deals with some of the general lines of reflection developed by the "young" narratives of the last millennium and, specifically, the way in which all of them intervene in the battle for the meaning of the word "worker". A route of analysis of some recent novels is proposed where the vector of social class acts as a focus, as an ordering axis, but in a particular and concrete way, inescapably characteristic of the new millennium. To observe the frame of reference that some "children of the children of the working class" construct in the literary field, we choose the novel by Anna Pacheco (Listas, guapas, limpias, 2019) as an exemplary tool, that is, as a support from the to delve into the fictional and collective strategies that take place around the origin of class. Through it, then, we delve into the analysis of the new frames of reference that took shape in the last century and that work in a particular way with the worker referent.
\end{abstract}

\section{KEYWORDS}

Listas, guapas, limpias; social class; cultural field; workers memory; repoliticization 


\title{
1. Los hijos de los hijos de la clase obrera: hacia un análisis de las frecuencias
}

\author{
"Hijos de la bonanza" nos llamaban: \\ los que no conocieron ni la hambruna \\ ni las agudas larvas de estridencia \\ chillando en el oído por las bombas. \\ [...] \\ Aunque, a veces, es cierto, no era fácil, \\ simplemente intentamos ir viviendo. \\ Haciendo caso omiso al comezón, \\ al vacío que moraba en nosotros, \\ hijos de la bonanza; \\ los hijos de los hijos de la ira, \\ herederos de todos los despojos. \\ (Clark 2006: 15-16).
}

En el año 2006, Ben Clark publica un poemario titulado Los hijos de los hijos de la ira, galardonado con el XXI Premio Hiperión, y considerado como uno de los libros más significativos del nuevo milenio puesto que permite acercarse desde las claves y estructuras del lenguaje poético a la transformación histórica y la sentimentalidad colectiva de las nuevas generaciones. Concretamente, el poema con que inauguramos el presente estudio representa una muestra significativa del gesto: los supuestos "hijos de la bonanza" son, en la composición, sujetos que, aunque se encuentran separados de las experiencias históricas (del pasado traumático) de sus abuelos y abuelas, viven en un presente quebrado, azotado por la inestabilidad y la vulnerabilidad. Son habitantes sacudidos por "la comezón" que, sin embargo, se enfrentan a una narrativa sobre el tiempo habitado desde la que se insiste en el cariz favorable, en la condición de bonanza que instaura el régimen democrático. El poema (y el libro en general) se construye sobre un estado anímico, vital y político muy concreto: el vaivén y la incertidumbre de las nuevas generaciones que, a pesar de nacer en un tiempo "próspero", experimentan una serie de incomodidades y violencias que determinan su transformación; los hijos de la bonanza son, en realidad, "herederos de todos los despojos".

Hemos usado la composición de Ben Clark como disparadero porque, pensamos, nos permite introducirnos de lleno en el tema central que plantean los coordinadores del monográfico Política en la literatura, literatura en la política. Si entendemos, de acuerdo con esto, que la crisis del año 2008 y los sucesivos movimientos sociales del nuevo milenio son un hito repolitizador que tiene efectos en el escenario social y cultural, debemos habilitar entonces una línea interrogativa que trate de dar explicación a algunos de los "nuevos" relatos que circulan y que nos permita comprender, al mismo tiempo, tensiones como las acontecidas en el poema mencionado: ¿Qué proponen, a un nivel político, las últimas narraciones del campo cultural? ¿Cómo se pone en juego "lo social” en todas ellas? ¿Qué efectos palpables tienen los acontecimientos históricos del nuevo siglo en el escenario cultural? ¿En qué medida las muestras artísticas de los autores y autoras son resultado de movilizaciones sociales como el 15M, la Primavera Valenciana o el 8M? ¿Se construye, verdaderamente, un marco de referencia que repolitiza el escenario cultural y permite abrir otros inter- 
rogantes? En este punto, proponemos una investigación que no solo aborda la relación mencionada (repolitización-cultura), sino que lo hace desde un lugar específico, desde una focalización precisa: nos interesa, especialmente, observar cómo los acontecimientos transcurridos en España en la última década afectan e intervienen en la transformación de los sentidos sobre lo obrero. $\mathrm{O}$, dicho de otro modo: nos interesa observar los procedimientos que acontecen en el campo cultural y, más especialmente, en una de las variantes concretas, aquella que discute, niega o reelabora el debate de las clases sociales. Siguiendo las líneas de pensamiento que marca el monográfico, proponemos un estudio centrado en las ficciones de los autores y autoras “jóvenes” y en cómo estas se relacionan con los sentidos de lo obrero en un contexto en perpetua transformación. Queremos saber, en definitiva, qué escriben y qué narrativas proponen los hijos de los hijos de la clase obrera. ${ }^{2}$

En este sentido, tratamos de observar cuáles son los ejes motrices de sus narrativas, es decir, cuáles son sus frecuencias y sus lugares comunes. A este respecto, pensamos, la novela de Javier Pérez Andújar, Paseos con mi madre (2011), ${ }^{3}$ funciona como un anticipo puesto que sus ideasfuerza se repiten en novelas posteriores. La estructura básica ficcional (la visita del narrador al barrio de su infancia) se complementa con seis dimensiones diferentes que le permiten pensar y escribir en torno al universo de referencias, tensiones y violencias que lo envuelven y que se convierte en territorio común para otras narrativas. Dimensiones que pueden estructurarse, como decimos, en seis elementos habituales: el paisaje periférico marcado por la deslocalización, la llegada de la migración y el aislamiento físico y cultural; el mapa emocional, confeccionado a partir de la familia y los amigos, que funciona como conector entre el protagonista y la experiencia vivida de su clase social; la conciencia obrerista en una dimensión personal (familiar) e histórica, que le permite observar críticamente su origen y su postura política; la advertencia de las limitaciones culturales, es decir, el yo autobiográfico denuncia que el aislamiento del barrio no es solo físico, geográfico, sino también y sobre todo cultural, lo cual limita la creación de un relato propio por parte de los obreros.

Esta certeza le lleva al quinto eje, a enunciar una necesidad ineludible, aquella que da forma a la novela: crear narrativa propia desde y para la clase obrera. Frente a la circulación de discursos ajenos, el narrador propone apropiarse de las palabras en un gesto de "defensa" de su propia clase.

1 Conscientes de la problemática que encierra la noción de "lo joven", remitimos al estudio que realizamos en torno a ella como categoría histórica, en disputa, cuya significación remite a acepciones distintas según el enfoque elegido. Este se encuentra en el interior del monográfico Lecturas del desierto: nuevas propuestas poéticas en España (2018).

2 El estudio que presentamos en este artículo pertenece a una investigación más amplia donde postulamos la existencia de dos tipos de narrativas que se encuentran en el epicentro de las batallas culturales por el sentido de lo obrero: las narrativas de la carencia y las narrativas para la disputa. Mientras que las primeras ahondan en la reproducción de sentidos peyorativos sobre la clase obrera, la segunda trabaja de forma crítica con el referente, es decir, trata de reactualizarlo y ponerlo en valor al compás de las transformaciones históricas. Lo que proponemos, entonces, es ubicar las obras que trabajan con las memorias obreras en el interior de las narrativas para la disputa, como una variante de estas. Para más información, véase: Martínez Fernández, Ángela (2021). "Una genealogía de lo obrero en el campo cultural: narrativas de la carencia y para la disputa” (en prensa). Por otro lado, entiéndase que realizamos una generalización al afirmar que "queremos saber qué escriben los hijos de los hijos de la clase obrera" y que en realidad nuestro estudio se encuentra limitado al análisis de una novela por cuestiones de espacio. Para ofrecer una panorámica más amplia, debería tenerse en cuenta la publicación de los últimos testimonios, poemas, obras de teatro, muestras audiovisuales, etc.

3 En la novela citada, el autor evoca de forma autobiográfica, a través de los paseos por el río junto a su madre, el tiempo de vivencias en el periférico barrio de San Adrián del Besós: “Cuando vuelvo a San Adrián del Besós paseo con mi madre siguiendo la orilla del río [...] En nuestro paseo, nos ponemos a recordar. Mi madre viene con noticias remotas, y yo retrocedo hasta la más pura esencia de ser el hijo de la Isabel." (Andújar 2011: 11-12). 
Y, por último, la composición de la novela se completa con la aparición de la paradoja/contradicción central: en la creación del relato propio emerge la denominada "figura del impostor". El protagonista se describe a sí mismo como un sujeto contradictorio que, al tiempo que narra, se distancia también de su clase social. Reconoce su origen obrero, pero se aleja de él a medida que escribe, a medida que alcanza un lugar reconocible dentro del discurso literario y sus intereses se separan de los intereses del barrio. Así, pues, el narrador sabe que la creación de una narrativa barrial es necesaria, pero a medida que la construye y la enuncia, su condición obrera se encuentra en tránsito hacia el empoderamiento cultural. ${ }^{4}$

El funcionamiento, las dinámicas y los ejes centrales de Paseos con mi madre (2011) permiten intuir el rumbo que años más tarde continúan otras narrativas, aquellas que utilizan como material ficcional las memorias obreras y las reactualizan bajo los códigos del nuevo milenio (y las nuevas generaciones). Destacan, entre otras, La inmensa minoría (2014) de Miguel Ángel Ortiz; Feria (2020) de Ana Iris Simón; Ama (2019) de José Ignacio Carnero y la novela que aquí nos ocupa, Listas, guapas, limpias (2019) de Anna Pacheco. Desde la relectura generacional, los escritores y escritoras siguen la estela de los elementos centrales presentes en la novelística de Andújar y colocan a la clase social en el centro, la reconocen como el conflicto central del ejercicio narrativo, y se interrogan por las tensiones y violencias que funcionan a su alrededor ${ }^{5}$. Por ello, el presente artículo - acogiéndose al núcleo interrogativo del monográfico- pretende ser un espacio de exploración y análisis de una de esas muestras literarias, para observar con detenimiento cómo funcionan, qué modos de relación proponen con las memorias obreras precedentes y, en definitiva, qué relatos e imaginarios construyen los hijos de los hijos de la clase obrera. A este respecto, utilizamos Listas, guapas, limpias como un soporte, como una herramienta ejemplarizante cuyo análisis nos permite ahondar en dos aspectos complementarios: por un lado, en la propuesta particular de Anna Pacheco (estrategias narrativas, dirección ideológica...), pero por otro lado, también, en la sintonía de la que forma parte y que permite intuir una dirección común, una frecuencia compartida por otras obras y autorías del periodo ${ }^{6}$. El presente artículo es, definitiva, un

4 Nos referimos, pues, al "complejo del impostor" para decretar un estado identitario que, en la narrativa ficcional de la última década, toma forma con más fuerza. El sujeto que escribe experimenta una distancia consigo mismo que está atravesada por una desubalternización. A medida que el individuo logra adquirir conciencia narrativa, también experimenta un alejamiento con algunos de los elementos centrales de su clase social. Es una escritura, pues, conflictiva: se narra desde la conciencia obrera, pero se deja entrever que dicha narración escapa, a su vez, del carácter puramente obrerista, de desposesión de la voz pública. En una suerte de advertencia sobre la subalternidad, Andújar construye un yo autobiográfico que se distancia del barrio al tiempo que lo reivindica en su escritura. De ahí la escena final de la novela: "Mi madre me va contando en estos paseos nuestro linaje granadino [...] escucharé a mi madre paseando por el río Besós y atravesando las llanuras secas de su voz anciana iré comprendiendo que no tengo más raíces que un puñado de palabras que apenas se usan, que ni siquiera soy de un idioma, que en realidad pertenezco a una voz" [La cursiva es mía] (2011: 176). Una voz compleja, pero que en su en condición paradójica, no deja de ser una "voz obrera".

5 No casualmente, son Andújar y Pacheco los autores citados para el encuentro que se celebra dentro del ciclo "Narrativas periféricas", del colectivo Akelharre, en l'Espai La Figa (l'Hospitalet de Llobregat): los escritores son convocados, precisamente, por su condición ambivalente de autores-obreros. Tanto Andújar como Pacheco se convierten en referentes de una figura paradójica y contradictoria que, junto a Carnero, exponen en el relato las distancias y los acercamientos que parpadean entre lo cultural y su propia clase. Los impostores buscan a los fantasmas en un intento por capturar los referentes de su propio origen y hacer explícitas las jerarquías que experimentan en el terreno de lo literario.

6 Entiéndase que cada novela tiene sus matices, sus técnicas y sus posicionamientos ideológicos, pero nos interesa llamar la atención sobre la forma en que todas ellas parten de un gesto compartido y tocan de una u otra forma los mismos ejes. 
intento por continuar comprendiendo y perfilando las características centrales de una narrativa obrera que funciona bajo los códigos del siglo XXI y que recoge el testimonio de las memorias precedentes, pero lo hace desde la singularidad de las nuevas generaciones y los matices que traen consigo los cambios históricos y culturales.

\section{Listas, guapas, limpias: un fantasma en la fotografía}

En el mes de febrero del año 2019, la revista digital Playground lleva a cabo un Expediente de Regulación de Empleo que afecta a sesenta trabajadores y trabajadoras (la mitad de la plantilla), entre las cuales se encuentra la periodista Anna Pacheco. Es en ese periodo de suspensión laboral cuando la autora lleva a cabo la escritura de su primera y única novela, Listas, guapas, limpias. En ella, los ejes narrativos apuntan directamente a una crítica del discurso ascensional y a la hipotética muerte de las clases sociales: "Se han esforzado mucho en hablarnos del fin de las clases, y yo creo que se ha destruido la idea de clase obrera [...] La protagonista no sabe a la clase a la que pertenece, ni el poder político que tiene reconocerse en ella" (Pacheco 2019: en línea). La declaración de la periodista sintetiza la propuesta y la dirección ideológica de su obra, que emerge como una narrativa contraria al discurso clasemedianista, como un escenario para visibilizar los procedimientos que tienen lugar en la etapa previa a la conciencia de clase.

Los de mi generación crecimos con la idea de que siendo guapos, listos y estando limpitos el camino estaba hecho. [...] Toda esa "clase media" la proyectamos guapa, limpia y lista y todos queríamos pertenecer a ella. Creo que parte del conflicto que vive la protagonista es cuando se da cuenta que eso que le habían repetido hasta la saciedad puede no ser tan útil ni tan cierto. Entonces, todo se tambalea. De repente, le faltan muchas otras cosas que nadie le había explicado. [La cursiva es mía] (Pacheco 2019: en línea).

La autora advierte que el título mismo de la novela remite a un mantra aspiracional contra el que ella se rebela: el relato de las clases medias y la escapatoria del referente obrero. Un mantra que ya había desmontado años antes a través de su faceta de periodista en el artículo “iPrecarios todos? Las hijas de la clase obrera tienen su propio techo de cristal", publicado en la revista de la que posteriormente resulta despedida. En él, Pacheco denuncia el espejismo de la igualdad de oportunidades que se desarrolla durante la década de los años ochenta y noventa y cómo este tiene consecuencias fatales para los hijos de la clase obrera: "Durante años el discurso hegemónico se ha esmerado en hablar del "fin de las clases". Nos han aglutinado a todas en una imprecisa clase media para hacernos sentir mejor" (2017: en línea) ${ }^{7}$. La periodista afronta, pues, la escritura de una novela iniciática desde la condición de desempleada y a partir de un posicionamiento político e

7 Pacheco remite también a las nociones de "precariado" de Standing y a la obra de Owen Jones para cuestionar la hipotética muerte de las clases sociales: "Hablan del precariado como si todos los jóvenes perteneciéramos indistintamente a él. Los trabajos se han precarizado, pero no todos somos igual de precarios. No es lo mismo trabajar en un curro de mierda porque no te queda otra a trabajar en un curro de mierda mientras aprendes alemán y haces un máster en Berlín. No es lo mismo cobrar 900 euros, pero tener un colchón familiar y un piso de propiedad, a no tener nada de eso. Owen Jones lo explica muy bien en Chavs: la destrucción de la idea de clase obrera anula el debate y aniquila la posibilidad de progreso." (2017: en línea). 
ideológico que apunta, indudablemente, hacia la defensa explícita del referente obrero. No obstante, a pesar de las visibles conexiones entre Pacheco y su creación ficcional, esta misma declara que el personaje principal no es una recreación autobiográfica de sí misma, sino que pretende partir de su conciencia para extrapolarla a un relato general de lo obrero en el nuevo siglo: "La protagonista no soy yo, pero sí he remitido a un imaginario presente en mi entorno y el de mis amigos. Así, creo, podía hacer este salto de forma más prudente” (2019: en línea). A pesar de que su situación de desempleo y los referentes con que trabaja en la novela son familiares, cercanos a la escritora, la obra no es un ejercicio puramente autobiográfico, sino más bien genérico, de referencia a una clase en su conjunto; se narran en clave ficcional referencias propias de su entorno familiar, pero también y sobre todo de su clase.

Es la puesta en relato de un discurso obrerista lo que acerca a Pacheco, según la crítica, a otros novelistas como Juan Marsé, Miqui Otero, Elisa Victoria, Pérez Andújar o, en palabras de la propia autora, "Elena Ferrante, Vivian Gornick, Joan Didion [...] Valérie Mréjen, Anne Carson, Lucia Berlin, Elizabeth Strout, Tony Morrison, John Fante, James Salter, Carrère" (2019: en línea) ${ }^{8}$. Su narrativa se nutre de relatos previos donde el trabajo con la clase social y el género resulta determinante. La particularidad o, mejor dicho, el tratamiento concreto de Pacheco, sin embargo, se sostiene en un relato sobre el barrio que no lo celebra o lo idealiza, sino que "se pone de frente para inspeccionarlo metiendo el dedo, si es necesario, en toda su llaga” (2019: en línea). Así, desde la condición de desempleo de la autora y a partir de una herencia narrativa concreta, da forma a una novela en la que " $\mathrm{N}$ ", la protagonista de veinte años de edad, experimenta un verano de incertidumbres y tensiones políticas que no logra codificar ni resolver. Mientras cuida de su abuela, percibe varias transformaciones a su alrededor: la relación de amor-odio con respecto a los amigos del barrio (encarnados mayoritariamente en la figura de Yaiza), las tensiones familiares con la madre y la abuela (a través de la distancia generacional), y las nuevas amistades con los estudiantes de la Universidad que representan otra posición de clase: "El verano transcurre entre la torre y el barrio y el barrio y la torre. Nunca hacemos nada especial” (2019: 37). El hastío y la incomodidad determinan un relato adolescente que, a su vez, se complica con la presencia de Hugo, su novio "del barrio" y Pau, un nuevo chico del entorno universitario: la relación sexual con ambos extrema las contradicciones y la desubicación de la protagonista.

Del mismo modo que ocurre en la novela de Andújar, Pacheco añade a la trama ficcional básica (el verano de "N"), cuatro dimensiones atravesadas por la clase social de la protagonista que apuntan, en su conjunto, a ese estadio previo a la conciencia de clase; así, los niveles refieren al deseo sexual de "N", a la recuperación que realiza de las memorias obreras (tanto familiares como colectivas), a la búsqueda de un relato propio que nace de la desigualdad cultural de los barrios y, finalmente, a la percepción de sí misma como una impostora (en un sentido cercano al postulado por el narrador de Andújar). Todas las dimensiones están marcadas por el estado subjetivo de la

\footnotetext{
8 Elena Costa, en El Cultural, ahonda también sobre los referentes posibles de la novela: "Implacable en su retrato de una joven que busca su lugar en el mundo, Pacheco recuerda en algunos tramos del relato, por el desclasamiento y la mala conciencia social de su protagonista, al Marsé de Últimas tardes con Teresa y a la Sally Rooney de Conversaciones entre amigos, $\mathrm{y}$, en su feminismo y su mirada a la vida familiar y al pasado, a la Gornick de Apegos feroces pero sin su profundidad ni su nostalgia, aunque resulten impagables los retratos de ese padre serio, "de seis o siete palabras por hora", de Yaiza, la amiga de la infancia, o de la mejor amiga de su abuela, "Luludearriba"'” (2019: en línea).
}

De la protagonista solo se aporta la inicial del nombre como identificación. 
protagonista, que se encuentra en el momento previo a la conciencia obrerista, de modo que en algunas ocasiones se exploran de forma inconsciente, palpando los referentes que la rodean y que, en un futuro, se intuye que tendrán una lectura política por su parte. La propuesta de Pacheco presenta, así, una narrativa obrerista donde se visibilizan las jerarquizaciones y la recuperación de la memoria obrera, pero lo hace a través de un personaje que todavía no codifica todo ello de forma plenamente consciente. La construcción narrativa, pensamos, permite a los lectores descubrir junto a la protagonista la relevancia política de su entorno y sus comportamientos.

\section{Erotismo de clase: el descubrimiento de la sexualidad}

El primer elemento de caracterización de "N" se centra en el desarrollo sexual de la misma. No por casualidad, la novela comienza con la voluntad de ruptura que la protagonista muestra en relación a Hugo, su "novio del barrio". La entrada en la Universidad la distancia intelectualmente de él y le permite enunciar en clave crítica su relación con lo sexual: existe una insatisfacción permanente $y$, sobre todo, un elemento de inconformismo con los modelos que observa en el barrio (especialmente aquellos comportamientos sentimentales y sexuales que reproduce su amiga Yaiza). A través de una reflexión que convierte en histórica la falta de satisfacción sexual femenina, "N" advierte que el sexo con Hugo le resulta monótono e ingrato, al tiempo que las relaciones monógamas y estables que observa en el barrio le producen aburrimiento, no llegan nunca a colmar sus deseos: "No me imagino cómo puede vivir tranquila pensando que solo ha besado a un chico en todos estos años [...] Por ese motivo, yo me siento más independiente que Yaiza" (2019: 13). El terreno sexual y de las emociones se encuentra atravesado constantemente por su deseo aspiracional, por su afán de descubrir y aprender. Las relaciones son para ella estadios de superación que terminan cuando la otra persona no puede aportarle más. En este sentido, la figura de Ane, a quien conoce a través de la Universidad, marca el rumbo del deseo sexual de la protagonista, que se encuentra más cercano a un determinado "erotismo de clase". En una entrevista publicada en la revista online Vice, en conversación con el periodista Juanjo Villalba, Pacheco declara: "La configuración del deseo no es azarosa. En el deseo de la protagonista hay aspiracionalidad, además de que está atravesado por una cuestión de género. A la protagonista le encanta gustar" (2019: en línea).

Así, a través de Ane, conoce a Pau, un personaje procedente de la clase alta catalana y cercano al entorno universitario: con él, la fascinación por su clase social funciona en gran medida como un estímulo del deseo de la protagonista. Al imaginarse a ella misma imitando el comportamiento de Ane, el empoderamiento intelectual y cultural, los pensamientos sexuales afloran en detrimento del hartazgo rutinario que le genera Hugo. A través de los personajes enfrentados de Pau y Hugo, representantes de mundos sociales distintos, Pacheco construye un primer elemento de caracterización de la protagonista desde una perspectiva de género y de clase que recoge las contradicciones de "N": por un lado, identifica su insatisfacción sexual como un estado compartido con el resto de mujeres (especialmente con su abuela) y rechaza los comportamientos tradicionales, monótonos, de Yaiza; pero, por otro lado, codifica su deseo en la aspiración social, en el erotismo de clase que la protagonista descubre a tientas. Es, precisamente, su identidad como mujer-obrera lo que determina estas contradicciones. Al final de la novela, "N" le envía un correo electrónico a Hugo donde le explica su necesidad de separarse como una renuncia al destino prefijado de las abuelas y las madres: "La 
mayor parte de las relaciones del instituto no son para toda la vida. No somos nuestros padres [...] A nuestros padres no les importa eso de las aficiones parecidas" (2019: 138-139). La protagonista se encuentra en una etapa de descubrimiento que, sin embargo, está atravesada por su posición de clase y por los nuevos relatos del empoderamiento feminista; todo ello se percibe de forma intuitiva, sin recurrir a apoyos teóricos o culturales (como una especie de intuición guiada por el deseo y el erotismo), de manera que ocurren situaciones y sensaciones en torno a " $\mathrm{N}$ " que no proceden de un ejercicio reflexivo profundo, sino de la pura percepción adolescente, que está atravesada por el origen y los condicionantes materiales/culturales de su entorno.

\section{El terreno de las memorias obreras}

El segundo elemento y uno de los más decisivos en la construcción ficcional de la novela es la relación con las memorias obreras. Según Pacheco, el objetivo principal de la obra es revalorizar los relatos de clase que, durante la adolescencia, circulan en torno a ella sin darle significación política: "Era la historia de mi vecina, la historia de mi abuela, historias que antes nos parecían irrelevantes [...] pero que en el fondo están llenas de política” (2019: en línea). Contra la amnesia colectiva escribe, pues, Pacheco, pero lo hace desde una elección narrativa concreta: no existe nostalgia de clase en la protagonista, no hay melancolía idealista, sino más bien una visión cercana y familiar, plagada de contradicciones, del modo en que dicha memoria obrera le determina. En la conversación con el periodista Juanjo Villalba, Pacheco declara que su novela narra contra la mitificación de lo obrero. Es un tipo de revalorización de las memorias que tiene que ver no con la imagen histórica e idílica de la clase social a la que pertenece, sino con los recuerdos que la adolescente tiene sobre sus familiares y compañeros del barrio y que, en realidad, determinan su identidad y su futuro. En el intento por revalorizar las memorias obreras, construye una protagonista cuyo estado es previo a la conciencia de clase: de este modo recoge los relatos, las anécdotas y las costumbres de su clase desde una posición ambivalente, no-nostálgica. Hay una creación del universo narrativo obrero desde el cariño, desde la cotidianidad, pero también desde la crítica y el distanciamiento.

La protagonista repasa los recuerdos de su infancia y describe a las personas que le rodean, pero lo hace desde el desenfado de alguien que convive con ellos y que, por tanto, reconoce sus méritos, pero también critica y desprecia sus contradicciones. El estado previo a la conciencia de clase le permite a "N" desarrollar un fluido de recuerdos en los que su habitus está determinado por un espacio, de clase, que intermitentemente le agrada y le desagrada, pero que sobre todo le condiciona. ${ }^{10}$ En otra entrevista con Henar Ortega para la revista Nylon Spain, Pacheco advierte: "Ha sido violento, incómodo, frustrante y también algo doloroso. El momento que retrata la novela es

10 Usamos la noción de habitus siguiendo los postulados de Pierre Bourdieu, esto es, como proceso de conversión de los principios externos, como asimilación -hecha cuerpo- de las condiciones objetivas: "En otros términos, podría decirse que se trata de aquellas disposiciones a actuar, percibir, valorar, sentir y pensar de una cierta manera más que de otra, disposiciones que han sido interiorizadas por el individuo en el curso de su historia. El habitus es, pues, la historia hecha cuerpo. Producto de la historia, es lo social incorporado -estructura estructurada-, que se ha encarnado de manera duradera en el cuerpo, como una segunda naturaleza, naturaleza socialmente constituida [...] Es un estado especial que adoptan las condiciones objetivas incorporadas y convertidas así en disposiciones duraderas, maneras duraderas de mantenerse y de moverse (los brazos y las piernas están llenos de imperativos adormecidos), de hablar, de caminar, de pensar y de sentir que se presentan con todas las apariencias de la naturaleza (Bourdieu 1980b)" (en Gutiérrez 2005: 68). 
el de la vergüenza de clase previo al orgullo de clase" (2019: en línea). Desde ese estado subjetivo, "N" construye y recupera un tipo de memoria obrera que se sostiene en tres núcleos: el familiar, el de las amistades y el de los lugares de memoria. Los recuerdos del barrio en el que todavía habita, pero del que desea escapar, se encuentran atravesados por los familiares, por los compañeros de escuela y por los referentes espaciales y simbólicos de la memoria.

Así, en primer lugar, el núcleo familiar de " $\mathrm{N}$ " se codifica mayoritariamente en la figura de la madre y la abuela: son ellas las que funcionan como anclajes firmes del pasado de la protagonista. En el caso de la abuela, es el único personaje que "está inspirado deliberadamente y de forma más explícita en mi abuela real. Y algunos de los episodios narrados son directamente sus propios relatos" (2019: en línea). Desde el comienzo, la protagonista advierte que su recuperación de la "genealogía familiar invisible" no procede de la épica, no se encuentra atravesada por episodios heroicos de la Guerra Civil o la dictadura, sino más bien por acontecimientos del ámbito personal y menos trascendentales ${ }^{11}$. Es, sin embargo, en la narración de la vida misma de la abuela donde la épica histórica se ve compensada con las urgencias materiales, la emigración desde Andalucía hasta Barcelona, el matrimonio a una temprana edad y la vida dedicada a los cuidados del resto. Aunque no se mitifica la relación de los abuelos con el conflicto guerracivilista, la narración de las penurias materiales que viven o la subalternidad de la abuela ${ }^{12}$, en tanto mujer obrera durante el periodo franquista, resultan elementos de contraste. Así, se relata la llegada de la familia a Barcelona, procedentes de Jaén, y las condiciones en que viven los primeros años: "Primero vivieron diez en un sótano, que era la trastienda del colmado que regentaba mi abuela” (2019: 45).

La descripción de la abuela se encuentra determinada al mismo tiempo por otros dos personajes: el abuelo y Lulú. En un ejercicio de distancia y crítica histórica, "N" revisita las condiciones del noviazgo entre las generaciones precedentes: el abuelo, albañil en un pueblo jienense, "se apoderó de ella como quien se apodera de un saco de trigo; lo hizo por orgullo [...] Dice que el abuelo se la llevó a cuestas y que a la mañana siguiente ya estaba como casada" (2019: 151). La relación entre ambos se basa en una especie de transacción donde la mujer apenas cuenta con voluntad para decidir: las mujeres del pueblo son "raptadas" por los hombres y se inician en una rutina de obediencia y cuidados hacia el otro. En un recorrido similar se encuentra Lulú (Lurdes), la mejor amiga de la abuela y su vecina de arriba (de ahí el sobrenombre Luludearriba): procedente de Granada, llega a Barcelona en la década de los años sesenta con cuatro hijos a su cargo y así comienzan a vivir en casas fabricadas por ellos mismos en las barracas de Torre Baró, "sin electricidad ni luz amontonadas de forma anárquica” (2019: 45) ${ }^{13}$. Luludearriba y la abuela de la protagonista funcionan

11 “Todas las familias tenían más épica que la mía: algún abuelo represaliado por el régimen franquista, algún familiar exiliado a París, algún superviviente en un campo de concentración nazi, las memorias de un rebelde anarcosindicalista, las cartas de amor de alguien un poco poeta. La nuestra, no. Se sabía que el abuelo se alistó en el bando nacional más por supervivencia que por convicción política. El pueblo cayó en manos de fascistas al principio de la guerra civil. Prácticamente todo el mundo que quería estar tranquilo en el pueblo se unía al bando de los ganadores, todo el mundo en mi familia quería estar tranquilo." [cursiva nuestra] (2019: 150).

12 Usamos la noción de subalternidad en el sentido spivakiano, como la ausencia de agencia y la privación del lugar enunciativo en el espacio audible.

13 Lurdes trabaja, durante años, en la limpieza doméstica y no tiene formación escolar, por ello, la madre de la protagonista se encarga de leerle las cartas que recibe de Hacienda. Su marido, Antonio Pepeyo, trabajador en la fábrica de construcción de moldes, "murió un día de golpe, aplastado por una máquina" (2019: 49-51). El duelo por la pérdida de su marido, advierte "N", se produce en compañía y a través de las rutinas del barrio. 
como figuras metonímicas: dentro de su especificidad, de sus comportamientos distintos, responden a un tipo de mujer obrera, migrante, que asume el cuidado de la familia y se sobrepone a las dificultades económicas. Son estas mujeres las encargadas del bienestar de la protagonista y con las que convive durante toda su infancia y adolescencia.

No obstante, en la descripción que la protagonista realiza de la abuela y su entorno se explicitan también los prejuicios de esta que, a su vez, hereda la madre. La abuela asume recomendaciones o costumbres que van contra su propia clase social y tiene un discurso extremadamente crítico con Yaiza, de quien le desagrada el abandono de los estudios, el piercing y la forma de bailar. En una línea similar, y a pesar de su condición de andaluza migrante, la abuela tiene una actitud racista con la nueva clase obrera que llega al barrio. El diálogo con ella resulta significativo porque la protagonista advierte cómo ha perdido la capacidad de rememorar y conectar su situación de migrante con la de aquellos que llegan, actualmente, al territorio español. La memoria de los emigrados andaluces no se vincula con la de los sudamericanos o paquistaníes, sino que desemboca en un racismo de clase ${ }^{14}$. En este sentido, la descripción de la abuela y del universo familiar en general se lleva a cabo a través de un vaivén: la convivencia directa con ella, el cariño y la crianza compartida, permiten que la protagonista reconozca las penurias materiales de la familia, al tiempo que se muestra crítica con los comportamientos racistas y clasistas que reproduce desde su condición de mujer obrera. En la misma línea se encuentra el personaje de la madre: aunque comienza a trabajar como secretaria del doctor Belincoso en una clínica dental a los catorce años, no cotiza hasta los treinta, y es ella la encargada principal de los cuidados familiares. En una reflexión similar a la que establece Carnero en Ama (2019), la protagonista advierte que, debido al tiempo dedicado a los otros, su madre apenas muestra intereses o entretenimientos propios: "Pienso, en ese momento, en los hobbys que tiene mi madre y no me viene ninguno a la cabeza. Realmente pensaba que comprar era su hobby favorito" (2019: 33). Es ella quien educa a "N" a través de una serie de principios de clase inamovibles: entre ellos, por ejemplo, la distancia que existe entre los ricos y los pobres en el tratamiento de la belleza o la necesidad de invertir en aquello que resulta beneficioso para la salud, como un buen calzado: "Son una inversión, y en zapatos mejor no ahorrar" (2019: 130).

No obstante, los comportamientos maternos prejuiciosos generan una distancia entre ambas: " $\mathrm{N}$ " advierte que su madre es extremadamente crítica con los inmigrantes ${ }^{15}$, con los amigos más cercanos a la familia (en una suerte de "doble cara"), pero también y sobre todo con la gente que abandona los estudios o entra en ciclos de formación profesional. Su madre reproduce un discurso del esfuerzo más cercano a las clases dominantes que a las vivencias de la clase obrera: "Por eso hay que trabajar siempre. Esforzarse siempre. ¿Sabes lo que te digo? Si te esfuerzas, ganas" (2019: 135). ${ }^{16}$ En este sentido, la descripción del núcleo familiar se basa fundamentalmente en dos figuras

14 La novela, precisamente, revierte esta falta de conexión y explicita en la respuesta de "N" la relación directa que existe entre unos y otros, del mismo modo que ocurría en la novela de Andújar entre los migrantes y los andaluces de San Adrià.

15 En una retórica similar a la de la abuela, la madre realiza comentarios racistas que "N" transcribe: "Que mi madre haga comentarios culpables y antisemitas en el coche" (2019: 12) o "a estos vecinos los llamamos "los gitanos" aunque no sean gitanos. Mi madre asegura que decir eso no es racista” (2019: 13).

16 También, por otro lado, se muestra especialmente crítica con las amas de casa, hacia quien lanza recriminaciones: “Todas esas madres bien que van a tomar un café cada mañana con las otras madres después de dejar a los niños en la escuela. ¿Yo tomo algún café en un bar por la mañana? ¿Verdad que no? Huevonas [...] Pienso en ese momento en que, 
de mujeres obreras que, desde una extracción humilde, asumen el cuidado de la familia y aportan a "N" enseñanzas y una red de cariño ininterrumpido. Sin embargo, son estas mismas mujeres las portadoras de prejuicios y contradicciones de clase con las que la protagonista entra en conflicto. La memoria obrera es compleja, multidimensional y, sobre todo, cambiante: se reconocen las limitaciones materiales, el origen migrante, la subalternidad femenina, pero también los comportamientos racistas y la asimilación aconflictiva de una lógica ascensional clasemedianista.

El entorno de las amistades, por otro lado, se describe a partir de la rememoración que la protagonista realiza de su periodo en el colegio. Así, recuerda a varios amigos del barrio y sus diferentes destinos: Javier, estudiante de ADE, Laura, trabajadora en una panadería, Tono, auxiliar de enfermería, o Zanea, su amiga ecuatoriana, quien "estuvo años poniéndose una sudadera de Piolín que yo había descartado porque me parecía demasiado infantil para mis nueve años" (2019: 32). Todos ellos, hijos de clase obrera, o bien continúan la profesión de sus padres o consiguen, como "N", acceder a la Universidad. El recuerdo de los personajes de la infancia se entrelaza con los habitantes actuales del barrio, que sirven como una muestra de las lógicas patriarcales que aún persisten. La violencia de género que representa la familia Castejón o la relación embrutecedora, de manada, entre los chicos adolescentes se codifica desde parámetros que ella experimenta en tanto parte del entramado barrial. De esta forma, el fluir de conciencia le sirve a la protagonista para percibir todo aquello que continúa inamovible en el barrio y, a su vez, las transformaciones generacionales.

Por último, los lugares de la memoria obrera resultan asimismo significativos para la construcción del paisaje barrial y la subjetividad de la protagonista. Entendemos, con Pierre Nora (1984), que los lugares de la memoria remiten a escenarios históricos donde quedan codificadas actuaciones o elementos representativos de la configuración memorialística del país/ciudad/barrio, etc. Sin embargo, pensamos, las referencias que la protagonista menciona y que sirven como potenciadores del recuerdo, de un ambiente familiar y obrero determinado, no son lugares de memoria en el sentido histórico, de monumentos o esculturas, de señalizaciones trascendentales en el espacio público, sino precisamente elementos que remiten a un tipo de educación emocional. Espacios por los que la protagonista transita, en los que crea rutinas, y que al mismo tiempo la delimitan como parte de una clase social concreta. Los centros comerciales, los lugares de comida rápida, los programas de televisión, etc., aparecen como escenarios indispensables para provocar el recuerdo, se activan como plataformas de una memoria obrera familiar y al mismo tiempo colectiva. En este sentido, Andalucía aparece como el primer anclaje geográfico de las memorias migrantes de la familia: los padres, en un intento por enseñar a la protagonista "lo que ellos llamaban intensamente su tierra" (2019: 119), visitan el territorio andaluz un verano durante su infancia ${ }^{17}$.

Con mayor profundidad, la protagonista reconoce como espacios propios el piso de sus padres en la periferia catalana y, sobre todo, el bloque donde viven la abuela y Lulu: "Lo considero más o menos mío porque es aquí donde básicamente he hecho casi todos los deberes con alguna

\footnotetext{
en estas conversaciones entre mi madre y yo, solo reprochamos comportamientos a las mujeres, nunca hablamos de los hombres" (2019: 133). Aunque de forma intuitiva, la protagonista rechaza un comportamiento que considera perjudicial para el cuidado entre mujeres: su madre, a pesar de asumir los cuidados del hogar, adopta una actitud recriminatoria y paradójica hacia las amas de casa.

17 La llegada al pueblo evidencia la distancia que los padres presentan con respecto a los familiares que siguen viviendo allí y la drástica separación de la protagonista. Es la abuela, en este sentido, la que le permite rememorar Andalucía, sentir como cercanos sus relatos y sus expresiones, "cuchá, ea y eso es una chominá” (2019: 119), pero las tierras andaluzas no son para "N" más que un referente vago, casi una ensoñación que, sin embargo, delimita su pasado emigrante.
} 
telenovela de fondo: La Usurpadora, Rubí, Gata salvaje” (2019: 45). Junto a los lugares del espacio privado que determinan su crecimiento, "N" construye un mapa de los escenarios donde se desarrolla su vida pública. Aparecen referenciados frecuentemente Carrefour, Burguer King, el Corte Inglés, el Rey de la Gamba, la tienda 24 horas o Conforama. Todos ellos funcionan como asideros de la memoria familiar y colectiva de la protagonista puesto que es en los centros comerciales o los restaurantes de comida rápida donde comparte el tiempo con su madre, realiza las compras, se reúne con los amigos o donde, directamente, acuden para comer tras el entierro de Pepeyo, el marido de Lulú. Como en la novela de Andújar, donde el Pryca es un punto de referencia para el barrio, Pacheco da forma a un mapa privado y público de lugares en el que la memoria de la protagonista se activa. A partir de las referencias a los diversos escenarios, "N" relata episodios de su infancia y adolescencia que remiten a una educación emocional y cultural ligada a la clase obrera. No obstante, emerge también en el relato de la protagonista un distanciamiento con los lugares de la memoria que responde a ese proceso de evolución generacional: “Transitamos los mismos espacios que nuestros mayores, siendo otras distintas, y cuando ellos se mueren esos espacios adquieren otra dimensión" (2019: 11). A la manera de los recorridos por el río del protagonista de la novela de Andújar, "N" reconoce los espacios, la forma en que estos constituyen su identidad y sus rutinas, pero aprecia también una evolución con respecto a ellos, una variabilidad que responde a su propia evolución personal, generacional.

\section{Comprar libros en Carrefour: sobre la educación cultural y el relato propio}

Al observar de nuevo los lugares de la infancia y llevar a cabo un proceso de introspección hacia los lugares que conforman su memoria, la protagonista percibe e identifica, aunque solo de forma intuitiva, uno de los conflictos principales de la novela: la falta de educación cultural que recibe por parte de los padres. O, en otras palabras, la desventaja educativa en materia literaria que hereda de su entorno familiar y social. A este respecto, aunque es un episodio breve en la novela, resulta significativa la escena entre "N" y su madre mientras ambas realizan la compra:

Mamá, ¿por qué nos llevabais al Carrefour a comprar libros? -suelto yo de golpe- ¿Tanto os costaba llevarnos a librerías? La gente normal compra libros en librerías, no en el Carrefour. A mi madre se le quita la sonrisa por el momento niño y frunce el ceño. Me mira. No logro recordar cuánto se alarga mi discurso sobre las librerías y la importancia de comprar en librerías porque ¿sabes, mamá? los libreros te recomiendan libros y quizás autores de los que nunca he oído hablar a mi edad y debería haber oído hablar ya, de hecho debería haberlos superado, a mi edad, a mi edad, a mi edad, Salinger, Bolaño, Austen, Yeats, Kafka, Bukowski, Dostoievski, Woolf, Plath, los estoy conociendo ahora y por casualidad, mamá, sin ningún orden ni rigor, suerte que existe internet, qué tarde es para todo, mamá, las librerías, mamá, qué importantes son. He perdido toda mi vida leyendo literatura juvenil y ahora todo es un desastre. [Cursiva nuestra] (2019: 35).

Carrefour se convierte en el espacio cotidiano de la memoria familiar, pero también en un lugar que priva a la protagonista de construir una relación más "acertada" o fructífera con la cultura. Una relación, al fin y al cabo, pautada por la ordenación tradicional, aquella cuyos ritmos y pro- 
cesos de aprendizaje son establecidos por los agentes del campo cultural: "N" no ha leído a los autores y autoras reconocidas por el canon literario que, en palabras de Bourdieu, funcionan como ordenadores del sentido, como señas del recorrido previsible que existe en la profesionalización educativa. En la recriminación a la madre, la protagonista toma conciencia de que su educación cultural es fruto del azar, de la lectura entrecortada e intuitiva. Aunque no codifica el proceso desde una posición política explícita, la novela relata el momento exacto en que el personaje comienza a percibir las determinaciones que la rodean y que, aunque centradas en la figura de los padres, responden a costumbres y espacios propios de su clase social. Dado que " $N$ " se encuentra en el momento previo a la conciencia de clase (o a la confección de un relato obrerista), la escena se resuelve con el enfado y la recriminación personalista hacia los progenitores, incapaces de ofrecerle una educación literaria más elaborada, y desemboca en un conflicto directo con la madre dentro de Carrefour. ${ }^{18}$ Pacheco construye una disputa entre ambos personajes que, lejos de resultar anecdótica, reelabora ficcionalmente los postulados que, entre otros, desarrollan autores como Willis (2017), Rancière (2010) o Bourdieu y Passeron (2003): esto es, la autora adapta el análisis de la desventaja cultural de la clase obrera a unos códigos literarios donde la protagonista no esgrime un discurso crítico, no tiene conciencia de que esa "falta de lecturas" es un hecho relativo a sus condiciones materiales, pero sin embargo hace palpable en el relato que algo sucede. Algo que no depende de ella plenamente y que procede de su herencia simbólica.

El gesto se repite en otras novelas anteriormente mencionadas: así, por ejemplo, en Ama (2019) de José Ignacio Carnero el narrador relata un detalle del ámbito privado que extrapola como metáfora del funcionamiento colectivo: en las casas de las familias de clase alta siempre hay una luz junto a la cama porque tienen la lectura integrada como una costumbre. Sin embargo, en su casa, así como en la de otros compañeros del barrio, esto no sucede. No porque resulte imposible, sino porque no es habitual: "No sé por qué nunca se lo dije a mi madre, pero si se lo hubiera dicho, se las hubiese arreglado para instalarme una luz junto a la cama" (2019: 83). La luz, el silencio necesario o la amplitud de las habitaciones remiten a una desventaja material para el desarrollo del pensamiento cultural. Los padres fomentan la educación del protagonista, pero lo hacen desde la falta de herramientas previas para ello, sin las costumbres materiales y simbólicas correspondientes a las clases altas. Según Pacheco, a pesar de los cambios históricos del nuevo milenio, la dimensión cultural de los barrios y sus respectivos regímenes de subalternidad se mantienen intactos. ${ }^{19}$ En sus últimas declaraciones, la periodista afirma que el aislamiento cultural y educativo sigue vigente y determina a los hijos de la clase trabajadora; aunque existen nuevas herramientas

18 La distancia entre la educación cultural y los padres se repite, de nuevo, en la anécdota que la protagonista relata sobre el momento en que resulta ganadora de un concurso de relatos de la escuela: en el cuento, "N" convierte al padre en un superhéroe capaz de conducir todos los transportes posibles y salvarla de la destrucción del mundo. Cuando se lo entrega, no obstante, este no comprende el uso que la hija realiza de la ficción y guarda el relato en su autocar, como un elemento cuyo valor simbólico no está en la narración, sino en otro lugar: “-Los carnets son para trabajar. Qué exageradarespondió mi padre el día que le mostré las páginas del cómic. Las observó con detenimiento y no supo qué más decir. -Es como la gracia, papá. Yo sé que guardaba una copia del cómic enrollada como un pergamino en la guantera del autocar. Él nunca me lo dijo, pero se lo oí decir a mi madre" (2019: 41).

19 Al mencionar "los regímenes de subalternidad" nos acogemos a los postulados que, entre otros, desarrollan autores y autoras como Gayatri Spivak (1998), John Beverley y Hugo Achugar (2002), Guillermo Bustos (2003), Dipesh Chakrabarty (2010) y María José Vega (2003). En este sentido, hacemos referencia a las posibles transformaciones que acontecen en el acceso al discurso público por parte de sujetos pertenecientes al estatuto de lo subalterno (o, en palabras de Spivak, de lo inaudible). 
propias del espacio virtual y ello promueve la hipotética democratización del conocimiento, las fronteras (simbólicas) se perpetúan.

\section{El complejo del impostor y sus efectos de desdoblamiento}

En la distancia cultural que "N" percibe con sus padres y su entorno en general existe, pues, un reconocimiento sobre la dificultad de tener relato propio en un ambiente en el que la educación literaria no es habitual, pero destaca también la necesidad de tenerlo. La formación universitaria de "N" determina el último y el principal elemento de construcción de la novela: el denominado “complejo del impostor/a”. En la entrevista con Ramírez (2019), Pacheco declara que en la elaboración del personaje de "N" resulta decisiva la orientación universitaria, la elección de una carrera con pretensiones de aspiración social. El relato ascensional se reproduce desde el núcleo familiar y coloca a la protagonista en una posición de "superación" con respecto a los progenitores: la abuela se enorgullece de que " $N$ " sea la primera licenciada de la familia junto a su "primo Manuel" (2019: 46) y el padre insiste, en varias ocasiones, acerca de la necesidad de cursar una carrera orientada a "ADE o Derecho y dejar el arte para mis ratos libres" (2019: 55). La asimilación no conflictiva del relato ascensional coloca a la protagonista en un espacio, el universitario, desde el que aprende y descubre nuevos intereses. "N" asume que su evolución vital se encuentra separada de aquella que tuvieron sus padres y, por tanto, debe trazar un camino distinto que no reproduzca el destino de clase, sino que lo "mejore" y lo supere.

Esto genera (y ahí reside la clave política de la novela) un estado de aburrimiento y hastío perpetuo con el barrio ${ }^{20} \mathrm{y}$, sobre todo, con las amistades, que se encuentran focalizadas en Yaiza: frente a los recuerdos y las experiencias compartidas en la adolescencia (pequeños hurtos en los centros comerciales, visitas a los lugares de comida rápida, fiestas compartidas, etc.), Yaiza "elige" un destino diferente al de la narradora (trabaja como esteticien en un Depiline (2019: 16)), mantiene una relación prolongada y monótona con Carlos, su pareja, y no varía en los intereses generales, en las rutinas: "Leer el horóscopo tumbadas al sol es otro ritual del verano que cada vez aborrezco con mayor intensidad [...] Me produce una sensación de continuidad y certidumbre, me entra la pereza" (2019: 20-22). Una pereza que, sin embargo, se convierte paulatinamente en aborrecimiento: "N" comienza a ver a Yaiza desde una distancia de clase que cataloga como "vulgar" algunos de sus comportamientos o decisiones estéticas (como "su piercing bolita de color blanco, que yo nunca me haría porque me parece vulgar" (2019: 23)) y juzga, también, sus decisiones amorosas con un novio que "la mayor parte de las veces, me repugna" (2019: 27).

"N" asume que el perímetro del barrio funciona como una frontera material y simbólica entre Yaiza y los nuevos amigos pertenecientes al entorno universitario, por eso "ellos nunca van a mi barrio y Yaiza no sale de él” (2019: 83). La falta de intereses que caracteriza a su amiga y el hastío de la protagonista se reproduce durante todo el verano y coloca su deseo en otro espacio, aquel donde pasan las vacaciones los compañeros de la Universidad ${ }^{21}$. El regreso de Ane de su casa de

20 "Los últimos meses he estado desaparecida, las tardes con la pandilla del barrio cada vez son más infrecuentes y a la mayoría de ellos no los veo desde la cena de navidad" (2019: 18).

21 "Ane veranea en Calella de Palafrugell y la verdad es que no me ha invitado. Quedo con Yaiza porque no tengo más planes. Eso no se lo he dicho" (2019: 84). 
vacaciones permite a la protagonista escapar de la monotonía barrial y acceder al entorno de la clase alta. No obstante, la asistencia a una de las fiestas que organizan los amigos de Ane supone un punto de inflexión: en ella, escapa al aburrimiento y la pereza que le provoca Yaiza, pero descubre el abismo que la separa de los jóvenes universitarios y se convierte, entonces, en una impostora, en un fantasma cuya identidad se encuentra a medio camino entre una y otra clase. La fiesta se celebra en uno de los pisos céntricos ubicados en el Eixample, "con techos altos", donde la mayor parte de los asistentes son "estudiantes de Humanidades, Políticas y Periodismo" (2019: 63). Las conversaciones giran en torno a referencias culturales y políticas que " $N$ " no controla: la película coreana de Park Chan-Wook, discos de música indie, reflexiones teóricas sobre el feminismo, recitales improvisados de poesía, discusiones sobre posicionamientos políticos, etc.

Frente a la actitud activa y desenvuelta de Ane, la narradora siente un malestar constante y la necesidad de pasar desapercibida: "Yo me senté en un lado del sofá deseando que nadie me preguntara nada" (2019: 64). Percibe de forma intuitiva, visceral, un complejo de clase que le hace apreciar el abismo que existe entre las referencias culturales de los asistentes y las suyas propias, aprendidas todas a través de los programas de televisión o los discos de música de sus padres. El complejo de clase de "N" le provoca una psicosis en la que imagina que el resto advierte su condición de inferioridad y sienten compasión por ella. Es en ese momento cuando la protagonista percibe que se encuentra en un lugar identitario confuso: ni se ajusta a la visión ascensional e idealizada que la familia proyecta sobre ella, ni se siente cómoda con el ambiente universitario cuyas referencias culturales no puede, ni sabe, manejar. Reconocerse como una figura "a medio camino" (ni Ane, ni Yaiza), como una impostora en ambos territorios de clase, le provoca un malestar físico e identitario: "Pasé toda la noche con un vacío en el estómago [...] Era la primera vez que experimentaba esa sensación, como de derrota por no encajar o no estar a la altura" (2019: 71). En una de las entrevistas que concede la escritora, esta afirma que en realidad la asistencia a la fiesta es un punto de inflexión en el que la desubicación de "N" se extrema, se radicaliza, pero ella no es capaz de comprenderla, no puede todavía codificar el malestar como una distancia de clase: "Es un momento muy importante porque ciertamente no tiene ni idea de qué le pasa. No sabe por qué se siente completamente fuera de lugar, incapaz de hablar con las palabras precisas" (2019: en línea).

El malestar, sin embargo, evoluciona hacia una sensación de curiosidad e incredulidad cuando Ane le confirma que Pau, uno de los asistentes, quiere conocerla. La relación entre ambos evoluciona, en detrimento de Hugo, y la protagonista descubre un nuevo estado en el que, al margen de los encuentros sexuales, desarrolla una sensación ambivalente: la capacidad intelectual de Pau le genera al mismo tiempo atracción e incomodidad. Las enseñanzas que aprende junto a él se ven contrarrestadas cuando percibe que su voluntad, su capacidad para sorprender y demostrar al otro, se ve constantemente subyugada a la iniciativa de Pau: "Cuando caminábamos me sentía torpe, como si él pudiera torcer en cualquier momento a la derecha y yo pasara de largo, revelando toda la verdad, que no me sabía ningún camino y, en realidad, lo estaba siguiendo todo el rato a él" (2019: 99). "N" se coloca, involuntariamente, en el lugar que Yaiza representa para ella y eso la somete a una vergüenza de clase que le obliga en alguna ocasión a ocultar la verdadera profesión de sus padres. ${ }^{22}$ Sin embargo, la tensión identitaria se "resuelve", en las últimas páginas de la

22 "Era la primera vez que estaba en la cama con una persona de mi edad con padres universitarios. Yo le dije que mi madre trabajaba en una clínica dental y que mi padre era chófer. Era el recurso que utilizaba para no decir "transportista" y "secretaria”. Al momento me sentí mal por eso, por haber hecho eso otra vez, pero tampoco me atreví a corregirlo." (2019: 102). 
novela, a través de un gesto político que Pacheco identifica como el estado previo a la conciencia. Así, precisamente en su relación con el joven universitario, aflora un reconocimiento intuitivo de su origen obrero que acontece a través de lo sentimental. En una de las conversaciones que tiene lugar entre ambos, Pau denuncia las escuelas infantiles y la irresponsabilidad de los padres que deciden llevar allí a sus hijos; en un gesto poco frecuente, la protagonista responde:

-No, a ver, si a mí me parecen muy bien todas esas escuelas, solo digo que el apoyo de la familia no siempre es tan fácil y que no todas las familias pueden implicarse tanto, ¿ sabes?- Sigo dubitativa-. Además, piensa dónde estudiaste tú y si eso puede pagarlo todo el mundo [...] ¡No me puedo creer que no te des cuenta de que eso que tú has hecho no puede hacerlo todo el mundo! -Me sorprendo a mí misma por la convicción y el aplomo con que verbalizo esta frase. Me siento orgullosa-. Antes que echar la culpa a los padres, ¿no es mejor que todas las escuelas públicas sean buenas? (2019: 117).

Es este el primer y único momento de la narración en que la protagonista defiende intuitivamente su origen de clase. Se desprende, por unos momentos, de la vergüenza y el complejo para enfrentarse con Pau en un diálogo que coloca en primer plano el determinismo de la clase trabajadora que ella misma experimenta. La escena se complementa, ya en las últimas páginas de la novela, con la imagen de "N", su madre y su abuela, en dirección hacia el médico mientras atardece sobre "los bloques de protección oficial". Es en ese momento en que observa el barrio y la familia, las vecinas en los balcones y el ruido de los perros, cuando la narradora declara: "El silencio de la tarde es espectral, como si en todos los pisos la gente estuviera alargando la última siesta de la última tarde del verano. Mi madre está guapísima iluminada de esa forma, y por algún motivo esa imagen me reconforta" (2019: 169) ${ }^{23}$. Es la madre ahora quien está guapa, no la imagen idílica de la hija, vista desde la óptica del relato ascensional. Pacheco resuelve la tensión identitaria de la protagonista, su complejo y alejamiento del barrio, con un gesto narrativo que permite tan solo intuir el desarrollo vital de "N": la distancia con los intereses de la adolescencia y los referentes culturales del barrio ha tenido lugar, pero ello no impide que sea posible reconocer su origen de clase y la sensación reconfortante y hogareña que le produce. En ese estado previo a la conciencia, "N" es un fantasma, una impostora a medio camino entre dos estratos sociales que todavía en el nuevo milenio generan tensiones al encontrarse.

\section{Conclusión: una posible línea de sentido}

Listas, guapas, limpias es una apuesta particular por mantener vivo el referente obrero. Una apuesta que trabaja, es evidente, desde el plano de la crítica y desde el reconocimiento al propio origen; pero lo verdaderamente significativo, pensamos, es el modo en que todo ello se lleva a cabo a partir de una serie de decisiones literarias y estéticas que traducen el gesto político al terreno ficcional (a la confección de la historia de "N"). En este sentido, el procedimiento de autoficción se complejiza puesto que no alude a una identificación autora-personaje, sino a un reconocimiento

23 "Al fondo al oeste, la cuadrícula exacta y precisa que forman los bloques de protección oficial se iluminan de un modo distinto por la luz anaranjada de la última hora de la tarde. Se oyen los ladridos de algún perro y la mujer de Benito, que siempre está asomada en el balcón de enfrente, nos saluda con efusividad llamándonos por nuestros nombres” (2019: 169). 
colectivo entre la experiencia familiar y social de la autoría y el referente comunitario de su propia clase social: Pacheco no trabaja con un material privado, individual, sino con los territorios comunes de lo obrero. La obra es, en conjunto, una aplicación concreta y específica de lo que ella misma defiende de otra forma en su trabajo como periodista; es un dispositivo que toma el intento por reactualizar el referente obrero y lo traslada a los estándares del campo cultural. Más allá de la especificidad de la novela, Listas, guapas, limpias se sostiene sobre una serie de ejes compartidos que apuntan hacia la existencia posible de una línea narrativa propia del nuevo milenio. Una línea que atendiendo a su diversidad se basa en el impulso común por resignificar lo obrero y que está protagonizada por los hijos de los hijos de la clase obrera o, en palabras de Ben Clark, por "los hijos de la bonanza / herederos de todos los despojos". Son estos sujetos, protagonistas históricos del nuevo siglo, quienes parecen esgrimir una postura política que subyace en sus obras ficcionales: la posibilidad de comprender el contexto y la propia identidad desde los parámetros de la clase social de procedencia. En este sentido, lo obrero no se abandona ni se sustituye por otros conceptos de reciente aparición, sino que se rescata, se remueve, se toca. En esta línea o impulso narrativo queda patente no solo el cariño y el reconocimiento al origen de clase, sino también la voluntad por hacerlo posible en el nuevo milenio, cuando el relato mayoritario tiende a olvidarlo o esconderlo. Nos preguntamos, no obstante, si todo aquello que la novela de Pacheco o las obras de Andújar, Carnero, Ortiz o Simón plantean será un efecto prolongado de la repolitización o si quedará anulado, en el futuro, por las narrativas hegemónicas que vendrán.

\section{Referencias bibliográficas}

Beverly, J.; \& Achugar, H. (2002). La voz del otro: testimonio, subalternidad y verdad narrativa. Ciudad de Guatemala: Universidad Rafael Landívar.

Bourdieu, P. (2007). El sentido práctico. Buenos Aires: Siglo Veintiuno editores.

. (2010). El sentido social del gusto: elementos para una sociología de la cultura. Buenos Aires: Siglo Veintiuno editores.

Bourdieu, P.; \& Passeron, J. C. (2003). Los herederos: los estudiantes y la cultura. Buenos Aires: Siglo Veintiuno editores.

Bustos, G. (2003). Enfoque subalterno e historia latinoamericana. Nación, subalternidad y escritura de la historia en el debate Mallon-Beverly. In C. Walsh (Ed.), Estudios Culturales Latinoamericanos: retos desde y sobre la región andina (pp. 215-242). Quito: Universidad Andina Simón Bolívar-Abya-yala.

Chakrabarty, D. (2010). Una pequeña historia de los estudios subalternos. In P. Sandoval, Repensando la subalternidad: miradas críticas desde/sobre América latina. Lima: Instituto de Estudios Peruanos.

Clark, B. (2006). Los hijos de los hijos de la clase obrera. Madrid: Hiperión.

Costa, E. (2019). Reportaje sobre Listas, guapas, limpias. El Cultural. https://elcultural.com/listas-guapas-limpias

Gutiérrez, A. B. (2005). Las prácticas sociales: una introducción a Pierre Bourdieu. Buenos Aires: Ferreyra Editor.

Ignacio Carnero, J. (2019). Ama. Madrid: Caballo de Troya.

Jones, O.(2013). Chavs. La demonización de la clase obrera. Madrid: Capitán Swing. 
López Fernández, Á.; Martínez Fernández, Á.; \& Molina Gil, R. (Eds.) (2018). Lecturas del desierto. Nuevas propuestas poéticas en España. Kamchatka. Revista de Análisis Cultural. https://ojs.uv.es/index.php/kamchatka/article/view/12662/12067

Ortiz, M. Á. (2014). La inmensa minoría. Madrid: Literatura Random House.

Pacheco, A. (2019). Listas, guapas, limpias. Madrid: Caballo de Troya.

Pérez Andújar, J. (2011). Paseos con mi madre. Barcelona: Tusquets Editores.

Ramírez, N. (2019). Todos queríamos pertenecer a la clase media, pero ni era tan útil ni tan cierta. El País. https://smoda.elpais.com/placeres/anna-pacheco-entrevista-libro-listas-guapas-limpias/

Romero Laullón, R.; \& Tirado Sánchez, A. (2016). La clase obrera no va al paraíso. Crónica de una desaparición forzada. Madrid: Akal.

Santolino, M.; \& Castillo Cerezuela, Q. (2019). Anna Pacheco i Javier Pérez Andújar: clase obrera, clase mitjana i literatura d'extraradi. El Crític. https://www.elcritic.cat/entrevistes/anna-pacheco-i-javier-perez-andujar-classe-obrera-classe-mitjana-i-literatura-dextraradi-44964

Simón, A. I. (2020). Feria. Madrid: Círculo de Tiza.

Spivak, G. (1998). ¿Puede hablar el sujeto subalterno? Orbis Tertius, 3, 175-235.

Standing, G. (2013). El precariado. Una nueva clase social. Barcelona: Pasado y Presente. . (2014). El precariado, una carta de derechos. Madrid: Capitán Swing.

Vega, M. J. (2003). Imperios de papel. Vías críticas del debate contemporáneo. Barcelona: Crítica.

Willis, P. (2017). Aprendiendo a trabajar. Cómo los chicos de la clase obrera consiguen trabajos de clase obrera. Madrid: Akal. 